Originalien

Monatsschr Kinderheilkd 2021 • 169:322-334 https://doi.org/10.1007/s00112-021-01134-8 Eingegangen: 11. Januar 2021

Angenommen: 26. Januar 2021

Online publiziert: 2. März 2021

(c) Springer Medizin Verlag GmbH, ein Teil von Springer Nature 2021

\section{Redaktion}

Berthold Koletzko, München

Thomas Lücke, Bochum

Ertan Mayatepek, Düsseldorf

Norbert Wagner, Aachen

Stefan Wirth, Wuppertal

Fred Zepp, Mainz

Seit Beginn der COVID-19-Pandemie (Corona-Virus-Disease; Corona-VirusErkrankung) bis zum 31.12.2020 wurden weltweit 81.484.663 COVID-19-Fälle gemeldet [1]. In Deutschland waren es bis zu diesem Zeitpunkt 1.785.270 Fälle, darunter 137.559 Kinder unter 15 Jahren [2].

Kinder entwickeln im Vergleich zu Erwachsenen oft nur geringe oder auch gar keine Symptome bei einer SARSCoV-2-Infektion [3-13]. Untersuchungen zur Übertragung von SARS-CoV-2 innerhalb des Haushalts und der Familie zeigen, dass die Kinder seltener infiziert sind als die Erwachsenen und sie in der Regel von Erwachsenen infiziert werden und nicht umgekehrt [14-22].

$\mathrm{Zu}$ Beginn der Pandemie im Frühjahr 2020 wurde in vielen Ländern ein Lockdown verhängt, so auch in Deutschland. Dabei wurden in Deutschland auch Schulen und Kitas geschlossen. Es gab lediglich eine Notfallbetreuung für Kinder von Eltern, die in der sog. kritischen Infrastruktur arbeiteten. Ab Mai 2020 wurden die Schulen und Kindergemeinschaftseinrichtungen unter hohen $\mathrm{Hy}$ gieneanforderungen schrittweise wieder geöffnet; zunächst in den „Teilbetrieb“ bis zum „Regelbetrieb unter Pandemiebedingungen“ nach den Sommerferien. Der „Regelbetrieb unter Pandemiebedingungen" sieht insbesondere das Einhalten der AHA+L-Regeln (Abstand, Hygiene, Alltagsmasken und Lüften) vor. Angesichts anhaltend hoher 7-Tage-Inziden-

Ursel Heudorf' $\cdot$ Katrin Steul ${ }^{2} \cdot$ Antoni Walczok $^{2} \cdot$ Rene Gottschalk ${ }^{2}$

${ }^{1}$ MRE-Netz Rhein-Main, Frankfurt, c/o Gesundheitsamt Frankfurt am Main, Frankfurt, Deutschland

${ }^{2}$ Gesundheitsamt Frankfurt am Main, Frankfurt, Deutschland

\title{
Kinder und COVID-19: Kontaktpersonen-Surveillance in Frankfurter Kitas und Schulen (August bis Dezember 2020)
}

zen in vielen Teilen Deutschlands wurden ab der 51. Kalenderwoche, also kurz vor Weihnachten, erneut Einschränkungen im Betrieb von Schulen und Kindergemeinschaftseinrichtungen in Kraft gesetzt.

Eine erste detaillierte Durchsicht der Meldedaten in Frankfurt am Main bis Ende Juli 2020 zeigte, dass Kinder am ehesten von Erwachsenen in ihrem privaten/ familiären Umfeld infiziert wurden. Allerdings entwickeln Kinder häufig keine oder nur leichte Symptome, weshalb sie oft nur als Kontaktpersonen (KP) getestet wurden. Angesichts der nur schrittweisen Wiedereröffnung der Kindergemeinschaftseinrichtungen ab Mai und der Vorgabe hoher Hygienestandards war allerdings die Wahrscheinlichkeit, sich dort $\mathrm{zu}$ infizieren, kaum gegeben [23].

Im Rahmen umfangreicher Testungen von Reiserückkehrern wurden zu Schuljahresbeginn auch viele Kinder aufSARSCoV-2 getestet. Ab Oktober 2020 war in Deutschland, auch in Frankfurt am Main, ein enormer Anstieg der SARS-CoV-2 Meldungen $\mathrm{zu}$ verzeichnen. Auch aus Kindergemeinschaftseinrichtungen und Schulen wurden Fälle bei Erwachsenen und Kindern gemeldet. Die positiv getesteten Fälle („Indexfälle“) wurden durch das Gesundheitsamt isoliert, und bei den ermittelten KP wurden auf freiwilliger Basis PCR-Tests auf SARS-CoV-2 vorgenommen. Eine erste Auswertung der Testungen in Schulen in Frankfurt am
Main bis zu 45. Kalenderwoche wurde kürzlich publiziert [24].

Nachfolgend sollen die Frankfurter Meldedaten SARS-CoV-2 insgesamt, aber insbesondere auch von Kindern über die Meldewochen bis zum 31.12.2020 und parallel dazu die Ausbruchsgeschehen in Kindergemeinschaftseinrichtungen sowie die Ergebnisse der Testungen der Kontaktpersonen vorgestellt und mit den Fragen diskutiert werden:

- Sind Kinder in Kindergemeinschaftseinrichtungen Treiber der Pandemie?

- Ist beim Auftreten von SARS-CoV-

2-Fällen in Schulen und Kitas das

Aussetzen der Präsenz in Teilen von Klassen oder Gruppen (oder der gesamten Einrichtungen) erforderlich?

\section{Material und Methode}

Die Anzahl und die Inzidenzen der SARS-CoV-2-Meldungen in Frankfurt am Main insgesamt sowie pro Meldewoche wurden aus SurvStat (https:// survstat.rki.de) sowohl für die Gesamtbevölkerung als auch für die Altersgruppen 0 bis 4 Jahre, 5 bis 9 Jahre, 10 bis 14 Jahre entnommen.

Ab Beginn des Schuljahres 2020/2021 wurden beiSARS-CoV-2-Meldungen bei in Kitas und Schulen Tätigen oder Betreuten sofort weitere intensive Recherchen angestellt. Der jeweils gemeldete Fall wurde als Indexfall bewertet. Hat- 
Hier steht eine Anzeige.

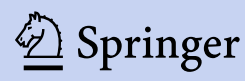


Tab. 1 Bevölkerung in Frankfurt am Main (gesamt und Kinder getrennt), SARS-CoV-2-Meldun-

gen und -Inzidenzen (bis Stand 31.12.2020)

\begin{tabular}{|c|c|c|c|c|c|}
\hline & Einwohner & $\begin{array}{l}\text { Anteil an Gesamt- } \\
\text { bevölkerung }\end{array}$ & $\begin{array}{l}\text { COVID-19- } \\
\text { Meldungen }\end{array}$ & $\begin{array}{l}\text { Anteil an } \\
\text { Meldungen }\end{array}$ & $\begin{array}{l}\text { Inzidenz/ } \\
100.000\end{array}$ \\
\hline Alle & 747.848 & - & 22.715 & - & 3037 \\
\hline 0 bis $14 \mathrm{~J}$ & 108.146 & 14,5 & 1717 & 7,6 & 1588 \\
\hline O bis $4 \mathrm{~J}$ & 40.880 & 5,5 & 431 & 1,9 & 1054 \\
\hline 5 bis $9 J$ & 35.034 & 4,7 & 526 & 2,3 & 1501 \\
\hline 10 bis $14 \mathrm{~J}$ & 32.232 & 4,3 & 760 & 3,3 & 2358 \\
\hline
\end{tabular}

te dieser in seiner infektiösen Zeit die Einrichtung besucht, wurden die KP erfragt und ihnen ein kostenloser PCRTest auf SARS-CoV-2 angeboten. Dieser wurde in der Regel 5 bis 7 Tage nach Kontakt mit dem Indexfall durchgeführt. Die Teilnahme war freiwillig.

Bei der Einstufung der KP wurden die Definitionen des Robert Koch-Instituts (RKI) zugrunde gelegt: Eine Person, die einen mehr als 15-minütigen ungeschützten „Face-to-face“-Kontakt zu einer infizierten Person hatte, wird als KP1 eingestuft; Menschen mit weniger als 15-minütigem ungeschütztem, direktem Face-to-face-Kontakt $\mathrm{zu}$ einer infizierten Person werden als KP2 eingestuft (z.B. Aufenthalt in einem Raum/ einer Klasse).

In Kitas wurden alle Kinder der Gruppe des Indexfalles bzw. auch weitere Kinder, bei denen enge Kontakte nicht auszuschließen waren, sowie die jeweiligen Betreuer als KP (in der Regel als KP 2) eingestuft. In den entsprechenden Gruppen wurde die Präsenz ausgesetzt. Kontaktpersonen der Kategorie 1 wurden quarantänisiert.

In den Schulen wurde den Mitschülern aus der Klasse des Indexfalles und den diese Klasse unterrichtenden Lehrern eine Testung angeboten. Waren Lehrkräfte Indexfälle, so wurden den von diesen Lehrern unterrichteten Klassen sowie den anderen Lehrern, die mit dem Indexfall entsprechenden Kontakt hatten, Testungen angeboten. In der Regel galten die Kinder der gleichen Gruppe/Klasse als KP der Kategorie 2. Darüber hinaus wurden die engen Faceto-face-Kontakte ermittelt, die als KP der Kategorie 1 gelten mussten. Diese wurden quarantänisiert. Die übrigen Kinder mit (fraglichem) Kontakt zum Indexfall konnten mit Mund-Nasen-Bedeckung weiter die Schule besuchen. In Schulen mit auch im Klassenraum bestehender und umgesetzter Maskenpflicht wurden keine weiteren Maßnahmen vorgenommen.

Die Rachenabstriche für die PCR-Testungen wurden von erfahrenen Teams verschiedener Rettungsdienste (Deutsches Rotes Kreuz, Arbeiter-SamariterBund) im Auftrag des Gesundheitsamtes Frankfurt am Main in der Einrichtung entnommen und im Bioscientia Institut für medizinische Diagnostik bzw. im Institut des DRK-Blutspendedienstes Frankfurt am Main mittels PCR [25] untersucht.

Die Ergebnisse der Testungen wurden deskriptiv mittels SPSS (Version 25) ausgewertet - differenziert nach Art der Einrichtung, nach Indexfall (Kind oder Erwachsener) und nach Untersuchungen zu Zeiten mit unterschiedlicher 7-TageInzidenz in der Gesamtbevölkerung. Für die paarweisen Gruppenvergleiche wurde das nichtparametrische Testverfahren Mann-Whitney-Test eingesetzt. Bei jedem Indexfall, der ohne Mund-NasenBedeckung in seiner infektiösen Zeit Kontakte in der Schule hatte, wurde ein „Vorgang“ angelegt. Weitere Indexfälle $\mathrm{zu}$ anderen Zeiten führten $\mathrm{zu}$ weiteren Vorgängen. Demzufolge entspricht die Zahl der Vorgänge der der Indexfälle $(n=274)$ und ist höher als die Zahl der betroffenen Einrichtungen $(n=218)$.

Angaben zur Bevölkerungsstruktur, zu den Schulen und Kitas, der Anzahl der Mitarbeiter und Betreuten wurden dem aktuellsten Jahresbericht des Bürgeramts für Statistik und Wahlen der Stadt Frankfurt am Main entnommen [26].

Da es sich um eine laufende Surveillance handelte, war ein Ethikvotum nicht erforderlich.

\section{Ergebnisse}

In Frankfurt wohnten (Stand Ende 2018)

747.848 Einwohner, darunter 108.146 $(14,5 \%)$ Kinder bis 14 Jahre [26]. Vom März bis zum 31.12.2020 wurden 22.715 COVID-19-Fälle gemeldet, darunter 1717 (7,6\%) SARS-CoV-2-Nachweise bei Kindern bis 14 Jahren. D.h., es wurden im Kindesalter bis 14 Jahren etwa halb so viele SARS-CoV-2 Nachweise gemeldet, als es ihrem Anteil an der Bevölkerung entsprochen hätte. Diese Unterschiede können auch anhand der altersbezogenen Inzidenz (Gesamtinzidenz vom März bis zum 31.12.2020) erkannt werden: Die Gesamtinzidenz in der Frankfurter Bevölkerung beträgt $3037 / 100.000$, bei Kindern bis 14 Jahren liegt sie mit 1588/100.000 halb so hoch. Beigenauerer Betrachtung zeigt sich, dass Kinder unter 5 Jahren mit 1054/100.000 die niedrigste Inzidenz aufweisen und die Inzidenzen mit zunehmendem Alter steigen: Bei den 10- bis 14-Jährigen liegt sie bereits bei 2358/100.000 und liegt somit nur wenig unter der Inzidenz der Gesamtbevölkerung (• Tab. 1).

Den Verlauf der täglichen SARS-CoV2-Meldungen insgesamt sowie der Meldungen der Kinder bis 14 Jahre vom März bis zum 31.12.2020 zeigt • Abb. 1. Auch in der zweiten Welle wurden nur vergleichsweise wenige Kinder bis 14 Jahre positiv auf SARS-CoV-2 getestet.

Die 7-Tage-Inzidenzen in Frankfurt am Main über die 10. bis 53. Meldewoche stellt $\square$ Abb. 2 dar. In der ersten Welle (Wochen 12 bis 18) traten Maximalwerte bis $36 / 100.000$ und 7 Tagen auf, danach blieben die 7-Tage-Inzidenzen unter 20/100.000, in den Kalenderwochen 23 bis 31 sogar unter 10/100.000. Im Zusammenhang mit dem Ende der Schulferien in Hessen und der umfangreichen Testung von Reiserückkehrern war in der 34. Woche ein Gipfel mit einer Inzidenz von 38/100.000 erkennbar. $\mathrm{Ab}$ der 41 . KW kam es zu einem starken Anstieg der 7-Tage-Inzidenzen bis zu einem Maximalwert von 319/100.000 der KW 45. In der ersten Welle blieben die altersbezogenen Inzidenzen im Kindesalter niedrig (max. 5,7/100.000 bei Kindern von 0 bis 4 Jahren; 16,5/100.000 bei Kindern im Alter von 5 bis 9 Jahren, 
Monatsschr Kinderheilkd 2021 · 169:322-334 https://doi.org/10.1007/s00112-021-01134-8

(c) Springer Medizin Verlag GmbH, ein Teil von Springer Nature 2021

\section{U. Heudorf · K. Steul · A. Walczok · R. Gottschalk}

\section{Kinder und COVID-19: Kontaktpersonen-Surveillance in Frankfurter Kitas und Schulen (August bis Dezember 2020)}

\section{Zusammenfassung}

Hintergrund. Angesichts der COVID-19Pandemie wird häufig unterstellt, dass Kinder Treiber dieser Pandemie sind, und dass beim Auftreten von SARS-CoV-2 in Schulen und Kindertagesstätten ganze Gruppen, Klassen oder die gesamte Einrichtung geschlossen werden müsse. Diesen Fragen wird anhand der Meldedaten in Frankfurt am Main sowie der umfangreichen Testungen der Kontaktpersonen (KP) in Schulen und Kitas nach dem Auftreten eines Indexfalles nachgegangen.

Methode. Die Meldedaten wurden aus SurvStat entnommen. Die Indexfälle aus Kitas und Schulen wurden isoliert, den KP auf freiwilliger Basis eine PCR-Testung auf SARS-CoV-2 angeboten - unabhängig davon, ob auf SARS-CoV-2 hindeutende Symptome aufgetreten waren oder nicht. Die tiefen Nasen-/Rachenabstriche wurden im Auftrag des Gesundheitsamtes der Stadt Frankfurt am Main durch Rettungsdienste vor Ort entnommen und nach etablierten Standards in 2 akkreditierten Instituten untersucht. Ergebnisse. Vom März bis zum 31.12.2020 wurden in Frankfurt am Main 22.715 COVID19-Fälle gemeldet, darunter 1588 (7,6\%) SARS-CoV-2-Nachweise bei Kindern bis 14 Jahren. Somit wurden bei Kindern bis 14 Jahren etwa halb so viele SARS-CoV-2Nachweise gemeldet, als es ihrem Anteil an der Bevölkerung entsprochen hätte. Der Anstieg der Inzidenz bei Kindern über die Wochen folgte zeitlich dem Anstieg der Inzidenz in der Allgemeinbevölkerung; die altersbezogene Inzidenz blieb unter der Inzidenz in der Allgemeinbevölkerung. Von der 35 . bis zur 52 . Kalenderwoche wurden 274 Indexfälle aus 143 Kitas und 75 Schulen gemeldet. Daraufhin wurden 7915 KP getestet. In Kitas wurde bei 4,5\% der erwachsenen KP und 2,5\% der Kinder-KP, in Schulen bei 0,9\% der Erwachsen-KP und 2,5\% der getesteten Schüler-KP SARS-CoV-2 nachgewiesen. Pro Indexfall wurde im Mittel deutlich weniger als ein KP positiv getestet. Die Rate positiver Befunde nahm mit steigender Inzidenz in der Gesamtbevölkerung zu. Ein größerer Ausbruch trat nicht auf.

Diskussion. Aus der Höhe und dem zeitlichen Ablauf der altersbezogenen Inzidenzen bei den Kindern in Frankfurt am Main ergaben sich keine Hinweise darauf, dass Kinder die "Treiber" der Pandemie sind. Die untersuchten $\mathrm{KP}$ in Schulen und Kitas wurden nur in einem geringen Prozentsatz positiv auf SARS-CoV-2 getestet. Bei fehlenden Hinweisen auf ein intensives Transmissionsgeschehen in den Einrichtungen kann/sollte der Besuch der KP unter Hygieneauflagen fortgesetzt werden, und es ergibt sich keine Notwendigkeit, ganze Gruppen, Klassen oder gar Einrichtungen zu schließen.

\section{Schlüsselwörter}

Schüler · Lehrer · Kindertagesstätten · Erzieher . Quarantäne

\section{Children and COVID-19-Data from mandatory reporting and results of contact person testing in daycare centers and schools in Frankfurt am Main, Germany, August-December 2020}

\section{Abstract}

Background. In face of the coronavirus disease 2019 (COVID-19) pandemic, the question that children are also drivers of this pandemic and that groups, classes, or the entire facility should be closed when severe acute respiratory syndrome coronavirus 2 (SARS-CoV-2) occurs in schools or daycare centers is always implied. These questions were investigated using the mandatory reporting data in Frankfurt am Main and the extensive testing of contact persons $(\mathrm{CP})$ in schools and daycare centers after the occurrence of an index case.

Method. The reporting data were taken from SurvStat. The index cases from daycare centers and schools were isolated and the CPs were offered PCR testing for SARS-CoV-2 on a voluntary basis, regardless of whether symptoms suggestive of SARS-CoV- 2 had occurred or not. Deep nasal/pharyngeal swabs were collected by paramedics on behalf of the public health department of the city of Frankfurt am Main, Germany, and tested according to established standards at two accredited institutes.

Results. From March to 31 December 2020, 22,715 COVID-19 cases were reported in Frankfurt, including 1588 (7.6\%) SARS-CoV-2 detections in children 14 years and younger. Thus, approximately half as many SARS-CoV-2 detections were reported in children up to 14 years of age than would have corresponded to their proportion in the population. In autumn 2020, the increase in incidence in children over the weeks followed the increase in incidence in the general population, the age-related incidence of children remained below the incidence in the general population. From week 35 to week 52, index cases were reported from 143 daycare centers and 75 schools. As a result, 7915 CPs were tested. In daycare centers, SARS-CoV-2 was detected in $4.5 \%$ of adult CPs and $2.5 \%$ of child CPs and in schools SARS-CoV-2 was detected in
$0.9 \%$ of adult CPs and $2.5 \%$ of student CPs tested. On average, less than $1 \mathrm{CP}$ tested positive per index case. The rate of positive findings increased with increasing incidence in the overall population. No major outbreak occurred.

Discussion. Regarding the level and timing of age-related incidences among children in Frankfurt am Main, there was no evidence that children were the drivers of the pandemic. Only a small percentage of the examined CPs in schools and daycare centers tested positive for SARS-CoV-2. In the absence of evidence of intense transmission in the facilities, $\mathrm{CP}$ attendance can/should continue under hygiene conditions and there is no need to close entire groups, classes, or even facilities.

Keywords

Pupils · Teachers · Day care centres · Quarantine 


\section{SARS-CoV-2-Meldungen in Frankfurt am Main}

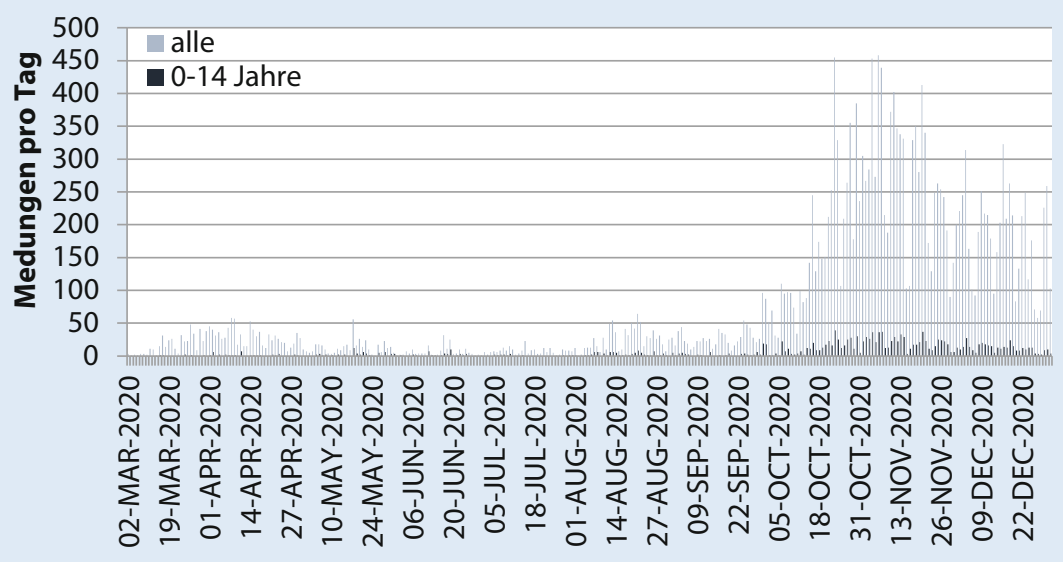

Abb. 1 ॥ SARS-CoV-2-Meldungen pro Tag in Frankfurt am Main vom März bis zum 31.12.2020 - Gesamtbevölkerung und Kinder bis 14 Jahre

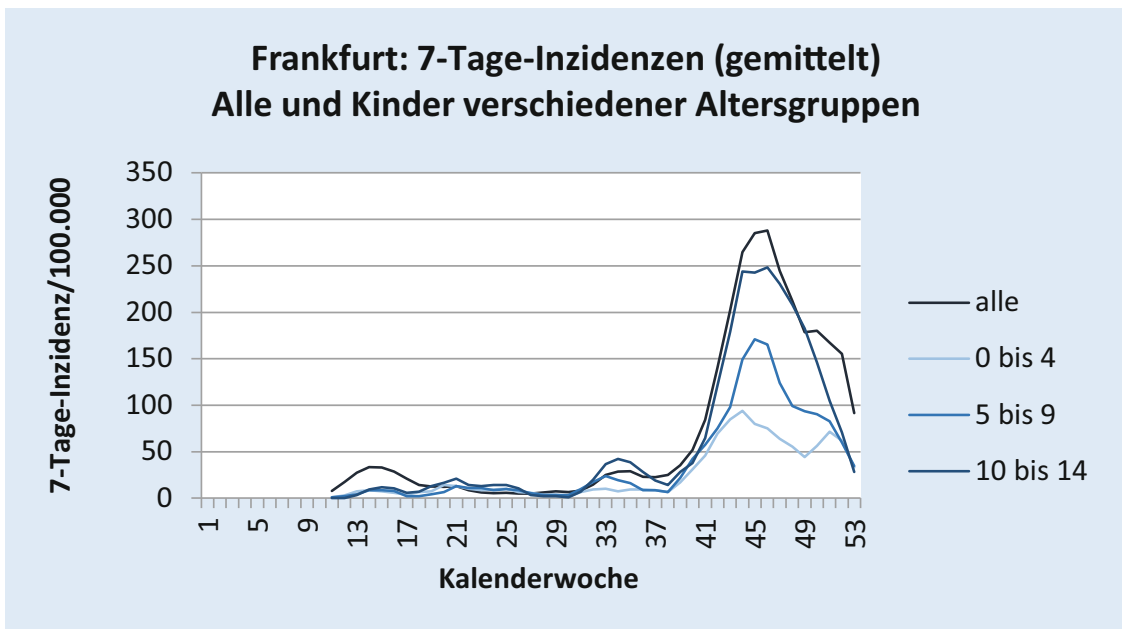

Abb. 2 ム Inzidenzen pro Meldewoche in Frankfurt am Main (Wochen 10 bis 53) - Gesamtbevölkerung und altersbezogene Inzidenzen (gleitende Mittel über 3 Wochen) bei Kindern bis 14 Jahre

17,8/100.000 in der Altersgruppe der 10bis 14-Jährigen). In der 34 . Woche mit der umfassenden Testung der Reiserückkehrer lag die altersbezogene Inzidenz der 10- bis 14-Jährigen mit 53/100.000 höher als die der Gesamtbevölkerung. Parallel zur starken Zunahme der Inzidenz in der Gesamtbevölkerung ab Oktober stieg auch die Inzidenz der 10- bis 14Jährigen und erreichte in der 45 . KW mit 289/100.000 fast die Gesamtinzidenz in der Bevölkerung. Die altersbezogene Inzidenz der jüngeren Altersgruppen stieg eine bis 2 Wochen später an und erreichte ein deutlich geringeres Niveau ( $\bullet$ Abb. 2).

In den 0 Tab. 2 und 3 sind die Ergebnisse der KP-Untersuchungen in der
35-52 Kalenderwoche in Kitas ( $\bullet$ Tab. 2) und Schulen (๑Tab.3) gezeigt. Mehr als zwei Drittel (69\%) der Indexfälle in Kitas waren Erwachsene (,in der Einrichtung Tätige"). In Kitas ließen sich 1062 Mitarbeiter und 3065 Kinder als KP mittels PCR-Test auf SARS-CoV-2 testen; 48 $(4,5 \%)$ der Erwachsenen und 78 (2,5\%) der Kinder wurden positiv auf SARSCoV-2 getestet. Die Betrachtung der Daten über die Phasen mit unterschiedlicher 7-Tage-Inzidenz (Phase 1: <50/100.000; Phase $250-<150 / 100.000$, Phase 3 $>200 / 100.000$, Phase $4<200 / 100.000$ ) zeigt, dass mit zunehmender 7-TageInzidenz in der Allgemeinbevölkerung auch der Anteil der positiv getesteten
Kontaktpersonen (Kinder und Erwachsene) zunimmt, wobei die Zunahme von der ersten bis zur dritten Periode nur bei den Kindern signifikant war (MW-Test $p 0,013$ ), angesichts der geringen Fallzahlen jedoch nicht bei den Erwachsenen (- Tab. 2).

In Schulen waren $73 \%$ der Indexfälle Kinder. Es wurden 897 Erwachsene und 2891 Schüler als KP getestet. Bei 8 (0,9\%) der getesteten erwachsenen KP (Kategorie 1 und 2) und bei $71(2,5 \%)$ der untersuchten Schüler wurde SARS-CoV-2 nachgewiesen. Die Positivenrate der erwachsenen KP zeigte nur einen geringen Zusammenhang mit der jeweiligen 7-Tage-Inzidenz ( $p>0,7$, nicht sign.). Bei den getesteten Kindern stieg die Positivenrate mit der 7-Tage-Inzidenz an und war in der 3. und 4. Phase signifikant höher als in der ersten Phase ( $p 0,047$ und $p 0,019$; sign.). In Grundschulen wurden KP häufiger positiv auf SARS-CoV-2 getestet als in weiterführenden Schulen (nicht signifikant). Besonderes Augenmerk ist hier auch auf die Integrationshelfer als Indexfälle zu richten. Diese Konstellation war mit den höchsten Raten positiv getesteter Kinder-Kontaktfälle assoziiert.

\section{Diskussion}

\section{Meldedaten, Inzidenz und Frage der Dunkelziffer}

Zu Beginn der Pandemie im Frühjahr, aber auch im Herbst 2020 mit einem starken Infektionsgeschehen und erheblicher Zunahme der positiv auf SARSCoV-2 Getesteten in der Gesamtbevölkerung blieben die altersbezogenen Inzidenzen im Kindesalter - insbesondere bei den Kindern unter 10 Jahren deutlich unter der Inzidenz in der Gesamtbevölkerung - in Frankfurt und in Deutschland insgesamt. Der Anstieg der Inzidenzen bei den Kindern folgte dem Anstieg der Inzidenz der Gesamtbevölkerung und ging ihr nicht voraus. Dies spricht dafür, dass nicht die Kinder dieErwachsenen anstecken (,Treiber der Pandemie“), sondern umgekehrt $[1,2]$.

Bereits im April 2020 wurde eine Kohortenstudie gefordert, um das Infektionsgeschehen weitgehend unbeeinflusst von der allgemeinen Teststrategie 
Hier steht eine Anzeige.

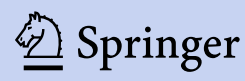


Tab. 2 Ergebnisse der Testungen von Kontaktpersonen in Kindertagesstätten in Frankfurt am Main auf SARS-CoV-2 - von KW 35-KW 52 (Mitte August bis 31.12.2020)

\begin{tabular}{|c|c|c|c|c|c|c|c|c|}
\hline \multirow[t]{2}{*}{143 Kitas } & & \multirow{2}{*}{$\begin{array}{l}\text { Vorgänge } \\
\text { Anzahl } \\
n\end{array}$} & \multicolumn{3}{|c|}{ Erwachsene } & \multicolumn{3}{|l|}{ Kinder } \\
\hline & & & $\begin{array}{l}\text { Getestet } \\
n\end{array}$ & $\begin{array}{l}\text { Pos. } \\
n\end{array}$ & $\begin{array}{l}\text { Pos. } \\
\%\end{array}$ & $\begin{array}{l}\text { Getestet } \\
n\end{array}$ & $\begin{array}{l}\text { Pos. } \\
n\end{array}$ & $\begin{array}{l}\text { Pos. } \\
\%\end{array}$ \\
\hline Alle & Alle & 164 & 1062 & 48 & 4,5 & 3065 & 78 & 2,5 \\
\hline \multirow{2}{*}{$\begin{array}{l}\text { Einrich- } \\
\text { tung }\end{array}$} & Kita, einschl. U3 & 137 & 950 & 46 & 4,8 & 2555 & 75 & 2,9 \\
\hline & Hort & 27 & 112 & 2 & 1,8 & 510 & 3 & 0,6 \\
\hline \multirow[t]{3}{*}{ Indexfall } & Erwachsene & 106 & 743 & 39 & 5,2 & 1858 & 65 & 3,5 \\
\hline & Kind & 56 & 299 & 9 & 3,0 & 1138 & 13 & 1,1 \\
\hline & Unbekannt & 2 & 20 & 0 & 0,0 & 69 & 0 & 0,0 \\
\hline \multirow[t]{4}{*}{ Nach KW } & $\begin{array}{l}\text { KW 35-39 } \\
\text { Inz. }<50 / 100.000\end{array}$ & 15 & 128 & 2 & 1,6 & 354 & 0 & 0,0 \\
\hline & $\begin{array}{l}\text { KW 40-42 } \\
\text { Inz. 50-<150/100.000 }\end{array}$ & 24 & 228 & 5 & 2,2 & 481 & 7 & 1,5 \\
\hline & $\begin{array}{l}\text { KW 43-47 } \\
\text { Inz. > 200/100.000 }\end{array}$ & 71 & 440 & 21 & 4,8 & 1353 & 41 & 3,0 \\
\hline & $\begin{array}{l}\text { KW 48-52 } \\
\text { Inz. }<200 / 100.00\end{array}$ & 54 & 266 & 20 & 7,5 & 877 & 30 & 3,4 \\
\hline
\end{tabular}

Tab. 3 Ergebnisse der Testungen von Kontaktpersonen in allgemeinbildenden Schulen in Frankfurt am Main auf SARS-CoV-2 - von KW 35-KW 52 (Mitte August bis 31.12.2020)
75 Schu-
Vorgänge Erwachsene
Kinder

len

Getestet Pos. Pos. Getestet Pos. Pos.

\begin{tabular}{|c|c|c|c|c|c|c|c|c|}
\hline & & $n$ & $n$ & $n$ & $\%$ & $n$ & $n$ & $\%$ \\
\hline Alle & Alle & 110 & 897 & 8 & 0,9 & 2891 & 71 & 2,5 \\
\hline \multirow[t]{2}{*}{ Schultyp } & Grundschule & 57 & 444 & 5 & 1,1 & 1387 & 40 & 2,9 \\
\hline & Weiterf. Schule & 53 & 453 & 3 & 0,7 & 1504 & 31 & 2,1 \\
\hline \multirow[t]{4}{*}{ Indexfall } & Erwachsene & 17 & 113 & 2 & 1,8 & 353 & 10 & 2,8 \\
\hline & I-Helfer & 5 & 26 & 0 & 0,0 & 57 & 4 & 7,0 \\
\hline & Schüler & 81 & 691 & 6 & 0,9 & 2315 & 55 & 2,4 \\
\hline & Unbekannt & 7 & 67 & 0 & 0,0 & 160 & 2 & 1,3 \\
\hline \multirow[t]{4}{*}{ Nach KW } & $\begin{array}{l}\text { KW 35-39 } \\
\text { Inz. }<50 / 100.000\end{array}$ & 34 & 323 & 2 & 0,6 & 1242 & 10 & 0,8 \\
\hline & $\begin{array}{l}\text { KW 40-42 } \\
\text { Inz. } 50-<150 / 100.000\end{array}$ & 23 & 221 & 3 & 1,4 & 559 & 13 & 2,3 \\
\hline & $\begin{array}{l}\text { KW 43-47 } \\
\text { Inz. > 200/100.000 }\end{array}$ & 27 & 188 & 2 & 1,1 & 580 & 23 & 4,0 \\
\hline & $\begin{array}{l}\text { KW 48-52 } \\
\text { Inz. }<200 / 100.00\end{array}$ & 26 & 165 & 1 & 0,6 & 510 & 25 & 4,9 \\
\hline
\end{tabular}

etc. beurteilen und die Dunkelziffer der asymptomatisch Infizierten abschätzen zu können [27]. Leider wurde und wird eine solche Kohortenstudie bislang nicht durchgeführt, sodass die Dunkelziffer nach wie vor nicht bekannt ist.

Es gibt jedoch Hinweise aus einer großen Erhebung in mehr als 100 Kinderkliniken in Deutschland: Dort wurden von März bis Mitte November 2020 über 110.000 PCR-Tests bei Aufnahme ner hohen Dunkelziffer bei Kindern in Deutschland auszugehen ist $[28,29]$.

Aus anderen Ländern liegen Ergebnisse verschiedener bevölkerungsweiter Untersuchungen auf SARS-CoV-2 vor: In der ersten Phase der Pandemie (Februar bis März) wurden in Island und in einer Region Norditaliens umfangreiche Tests auf SARS-CoV-2 in der Bevölkerung vorgenommen. In Island wurden bei einer gezielten Untersuchung von 9199 symptomatischen Personen und deren KP 13,3\% aller Untersuchten und 6,7\% der getesteten Kinder unter 10 Jahren positiv auf SARS-CoV-2 getestet. Bei 2 weiteren Populationstestungen waren $0,8 \%$ resp. 0,6\% der Getesteten SARS-CoV2-positiv, darunter keine Kinder unter 6 Jahren [30]. In Vo, Norditalien, wurden nach einem COVID-19-Fall in 2 Untersuchungszyklen $86 \%$ resp. $72 \%$ der Bevölkerung mittels PCR auf SARS-CoV-2 getestet. Die Response der Kinder unter 10 Jahren betrug $96 \%$ resp. $68 \%$. Insgesamt wurden $2,6 \%$ und 1,2 $\%$ der Untersuchten positiv aufSARS-CoV-2 getestet, darunter keine Kinder unter 10 Jahren [31].

Dies spricht in der Zusammenschau dafür, dass Kinder nicht als Infektionstreiber infrage kommen.

\section{COVID-19 in Schulen und Kinder- gemeinschaftseinrichtungen}

Im Rahmen der Bearbeitung der gemeldeten COVID-19-Fälle muss auch nach einer Tätigkeit oder einer Betreuung in Einrichtungen nach $\$ \$ 23,33,36$ und 42 des Infektionsschutzgesetzes (IfSG) gefragt werden ( $\$ 23$ : u.a. Beschäftigte in Krankenhäusern, Rehabilitationseinrichtungen, Arzt- und Zahnarztpraxen sowie Patienten; $₫ 33$ IfSG u. a. Lehrer, Erzieher, sonstiges Personal von Schulen und Kindergemeinschaftseinrichtungen und betreute Kinder in Schule und Kindergarten; $\$ 36$ IfSG u.a. Mitarbeiter in Altenpflegeheimen, Flüchtlingsunterkünften etc. sowie Altenpflegeheimbewohner, Flüchtlinge etc.). Laut Robert Koch-Institut waren am 31.12.2020 in Kindergemeinschaftseinrichtungen insgesamt 44.552 „Betreute“ unter 18 Jahren sowie 22.105 Tätige mit positivem SARSCoV-2-Test gemeldet [32]. Bei insgesamt 
14,6 Mio. Kitakindern und Schülern und insgesamt 2,17 Mio. Lehrern und in Kindergemeinschaftseinrichtungen Tätigen $[33,34]$ entspricht das $0,3 \%$ Betreuten und $1,0 \%$ der in diesen Einrichtungen Tätigen. Allerdings muss hier von einer erheblichen Untererfassung ausgegangen werden, da zu dieser Frage bis Ende September bei ca. einem Viertel der Fälle dem RKI keine Angaben übermittelt wurden, und der Anteil der fehlenden Daten zu dieser Thematik mit Zunahme der Inzidenz in der Bevölkerung ab Oktober auf inzwischen mehr als $50 \%$ stieg. Auch in Frankfurt am Main wurden diese Angaben wegen der erheblichen Arbeitsbelastung seit der 41. KW nicht mehr in SurvNet dokumentiert, sodass aus den Meldedaten hier keine gesicherten Erkenntnisse (mehr) gezogen werden können. Deswegen werden im Gesundheitsamt Frankfurt am Main bei Meldungen aus Kindergemeinschaftseinrichtungen ( $\$ 33$ IfSG) die Daten der KP-Testungen genutzt, um einen Überblick über die Situation in Schulen und Kitas in der Stadt zu erhalten.

In Frankfurt am Main wurden laut Angaben des Bürgeramts für Statistik im Jahr 2019 insgesamt 42.872 Kinder von 11.702 in Kitas Tätigen betreut. In den 177 allgemeinbildenden Schulen wurden 69.682 Schüler von 5849 Lehrern unterrichtet [26]. Von der 35. bis zur 52. Kalenderwoche wurden im Rahmen der KPUntersuchung 3065 in Kitas Betreute und 1062 in Kitas Tätige sowie 2891 Schüler und 897 Lehrer auf SARS-CoV-2 getestet. Das entspricht 9,3\% der in Kitas Tätigen und 7,5\% der Betreuten sowie 4,2\% der Schüler und 15,2\% der Lehrer. Obwohl es sich um ein gezieltes anlassbezogenes Testen von KP handelte, wurden vergleichsweise wenige positiv auf SARSCOV-2 getestet: 2,5\% der in Kitas Betreuten, 4,5\% der in Kitas Tätigen, 2,5\% der Schüler- und 0,9\% der Lehrer-KP. Bundesweit lag die Test-Positiven-Rate ab der KW $43>5 \%$ und ab der KW 49 $>10 \%$. Pro Indexfall wurden im Mittel 6 bis 8 Erwachsene und 19 bis 26 Kinder als KP getestet und darunter weniger als ein weiterer infizierter Fall gefunden. Mit Zunahme der Inzidenz von SARSCoV-2-Infektionen in der Allgemeinbevölkerung wurden auch mehr KP positiv getestet. Dies ist in Übereinstimmung mit einer großen Studie, basierend auf den Meldedaten aus England. Auch dort fanden sich enge Assoziationen zwischen der SARS-CoV-2-Inzidenz in der Bevölkerung und dem Nachweis von SARSCoV-2 in Schulsettings [35].

Auch unter hoher 7-Tage-Inzidenz (>200/100.000 Einwohner) in der Allgemeinbevölkerung wurde im Rahmen der Untersuchungen der KP von Indexfällen im Setting Kindergemeinschaftseinrichtung und Schule weniger als ein weiterer SARS-CoV-2-positiver Fall pro Indexfall detektiert. Dies und die niedrige Gesamtzahl der positiv auf SARS-CoV-2 Getesteten spricht weder für häufige Übertragungen noch für eine erhebliche Dunkelziffer nichterkannter asymptomatischer, aber infektiöser COVID-19Infizierter in den Einrichtungen. Dabei ist darauf hinzuweisen, dass positiv getestete KP nicht automatisch als Indiz für eine Übertragung in den Einrichtungen selbst gewertet werden können. Oftmals ergab sich bei genauen Recherchen, dass sich Indexfälle und KP im familiären oder im Freizeitumfeld infiziert hatten.

Dies stimmt mit den Erkenntnissen aus Hamburg überein: Dort hatten sich 292 (78\%) der insgesamt 372 zwischen den Sommer und Herbstferien mit SARSCoV-2 infizierten Schüler (Indexfälle) nicht in der Schule, sondern außerhalb mit SARS-CoV-2 infiziert, und nur bei $80(21,5 \%)$ der Fälle war eine Infektion möglicherweise in der Schule erfolgt. In dieser Zeit hatten 171 (36\%) der 472 Schulen SARS-CoV-2-Infektionen unter ihren Schülern gemeldet, jedoch nur in 17 Schulen (10\% der Schulen mit COVID-19-Meldungen bzw. 3,6\% aller Schulen) hat es vermutlich schulinterne Infektionen gegeben. Es wurde vermutet, dass der geringe Anteil schulinterner Infektionen darauf zurückgeführt werden könne, dass innerhalb der Schulen die Beteiligten die Hygieneregeln wesentlich disziplinierter einhalten als außerhalb [36].

Größere Ausbrüche, „Cluster“ oder ein „Superspreading-Event“, wie beispielsweise in einer Schule in Jerusalem [37] oder einer Schule in Hamburg [36], wurden in Frankfurt in der betrachteten Zeit nicht festgestellt. Auch die dem
RKI gemeldeten Ausbruchsgeschehen bis August 2020 zeigten, dass Ausbrüche in Schulen in Deutschland eher selten waren [38, 39].

Auch eine groß angelegte Studie in Sachsen, in welcher Blutproben von über 2000 Schülern im mittleren Alter von 15 Jahren sowie Lehrer aus weiterführenden Schulen in Dresden und verschiedenen Landkreisen in Sachsen auf Antikörper gegen SARS-CoV-2 untersucht wurden, ergab (Stand Oktober) weder Hinweise auf unerkannte Übertragungen in Schulen noch darauf, dass sich Schulen $\mathrm{zu}$ "hot spots" entwickelt haben [40].

Auch aus anderen Ländern wurden Ergebnisse von KP-Untersuchungen mittels PCR aus Rachenabstrichen von Kindern oder Personal in Schulen und Kindergemeinschaftseinrichtungen publiziert (• Tab. 4; [41-51]).

Einige kleinere Untersuchungen fanden bereits zu Beginn der Pandemie, noch vor dem Lockdown, in dem jeweiligen Land statt [41-46]. In dieser ersten Phase wurden in der Regel nur KP mit einer auf COVID-19 hinweisenden Symptomatik mittels PCR aufSARS-CoV-2 getestet. Nach der vorsichtigen und schrittweisen Wiederöffnung der Einrichtungen unter besonderen Abstands- und Hygieneauflagen wurde über weitere Ergebnisse von KP-Untersuchungen berichtet, wobei jetzt - mit zunehmender Testkapazität in den jeweiligen Ländern - alle KP getestet wurden, also unabhängig von einer etwaigen auf COVID-19 hinweisenden Symptomatik [47-49]. In den meisten dieser Studien wurden nur sehr wenige KP positiv auf SARS-CoV-2 getestet. Ausnahmen bilden ein Ausbruch im Februar in 2 Schulen in Frankreich [41], ein Bericht aus Kindergärten in den USA [47] und insbesondere ein großer Ausbruch in einer Schule in Jerusalem.

Nach der Wiederöffnung der Schulen in Jerusalem im Mai 2020 (und nachdem in einer Schule 2 Schüler positiv getestet worden waren (angenommene Indexfälle)) wurde bei 153 von 1164 (13,2\%) der Schüler und 25 der 152 (16,6\%) der Erwachsenen SARS-CoV-2 im Rachenabstrich detektiert (Superspreading-Event). Die Autoren beschreiben, dass es in dieser Zeit extrem heiß war, weshalb die Mitarbeiter und Schüler ihre Masken nicht 


\section{Originalien}

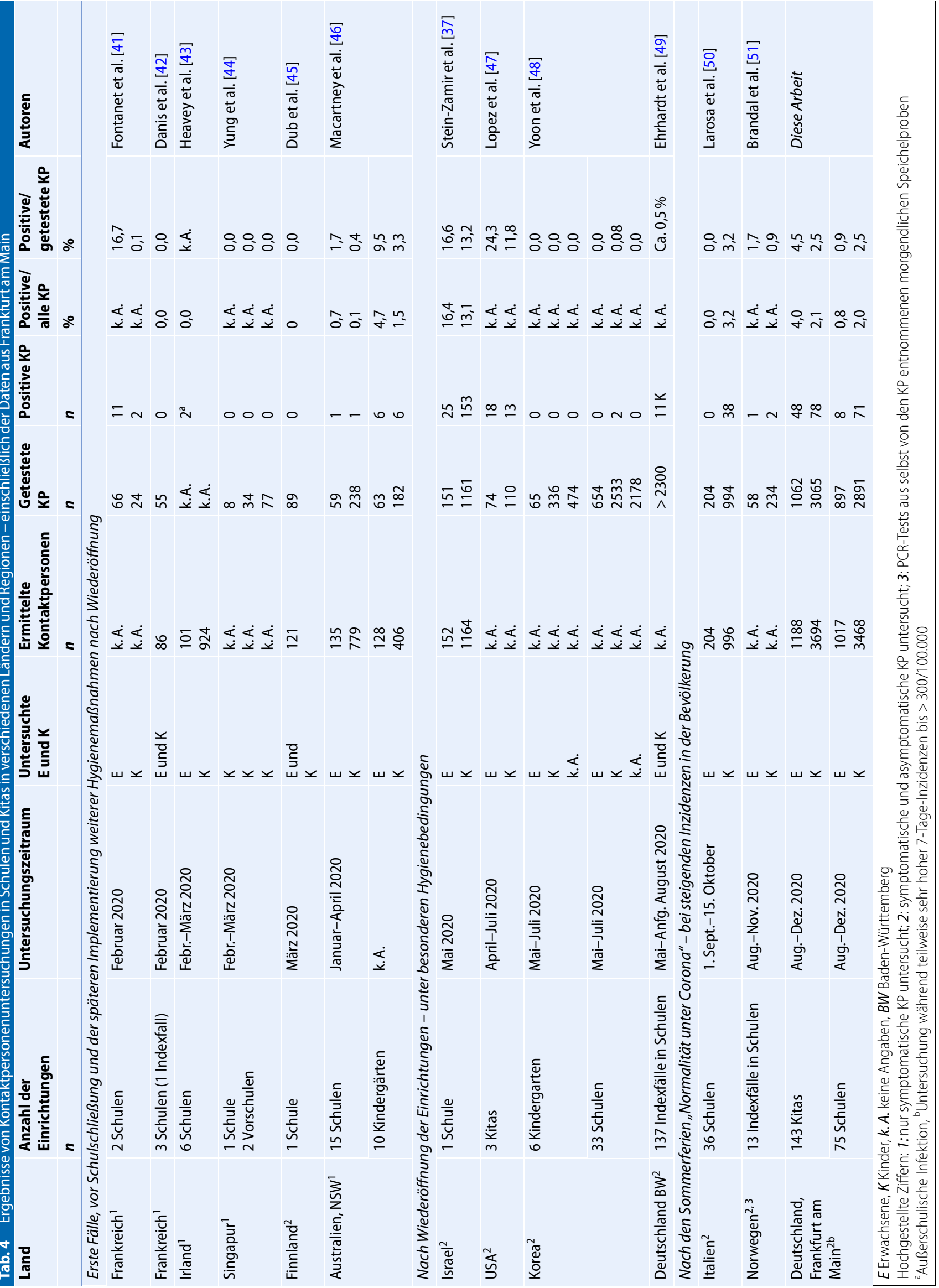


trugen; außerdem wird über eine extreme Enge in den Klassenräumen berichtet, mit 35 bis 38 Schülern in Klassenräumen mit 39-49 $\mathrm{m}^{2}$ [37].

Nach den Sommerferien, unter „Normalität unter COVID-19“, d.h. Präsenzunterricht bei Einhaltung von Abstandsund Hygieneregeln liegen bislang $2 \mathrm{Pu}-$ blikation vor: In der Provinz Reggio Emilia, Italien, wurden nach den Sommerferien bis zum Beginn der Herbstferien (15.10.2020) COVID-19-Fälle an 36 Schulen gemeldet und $1198 \mathrm{KP}$ untersucht. In dieser Zeit hatte die COVID19-Inzidenz in der Gesamtbevölkerung von weniger als 30/100.000 auf über 250/100.000 zugenommen. Keine der 204 untersuchten erwachsenen KP, aber 3,2\% der untersuchten Kinder wurden positiv auf SARS-CoV-2 getestet [50]. In Norwegen wurden vom 28.08.2020 bis zum 11.11.2020 KP von 13 Indexfällen in verschiedenen Schulen mittels PCR aus selbst entnommenen Speichelproben - also nicht Rachenabstrichen untersucht, darunter 234 Kinder und 58 Erwachsene. Zwei Kinder (0,9\%) und ein Erwachsener $(1,7 \%)$ wurde positiv auf SARS-CoV-2 getestet. Die 14-TageInzidenz war in der Untersuchungszeit von 20 auf 95/100.000 angestiegen [51].

Eine Übersicht über die Ergebnisse der oben genannten Studien im Vergleich mit den hier vorgestellten Daten aus Schulen und Kindergemeinschaftseinrichtungen in Frankfurt am Main gibt - Tab.4. Es ist leicht erkennbar, dass die Frankfurter Untersuchung die größte Erhebung darstellt.

Während alle Untersuchungen in der ersten Phase der Pandemie mit noch niedrigeren Inzidenzen erfolgten, stammen die Daten aus Frankfurt am Main aus dem Herbst 2020 mit teilweise sehr hohen 7-Tage-Inzidenz-Raten in der Stadt. Lediglich die Untersuchungen aus Italien und Norwegen [50, 51] umfassen auch die Situation nach den Sommerferien, d. h. Zeiten stark steigender Inzidenzen an COVID-19. Die Frankfurter Untersuchung berücksichtigt darüber hinaus die Situation bis zum Jahresende und somit eine lange Periode sehr hoher COVID19-Inzidenzen bis $>300 / 100.000$ in der Bevölkerung. Vor diesem Hintergrund ist die vergleichsweise niedrige Positiven- rate in den Frankfurter Einrichtungen umso bemerkenswerter. Es kann angenommen werden, dass dies auch auf die umfangreichen Hygienemaßnahmen in den Einrichtungen $(\mathrm{AHA}+\mathrm{L})$ mit möglichst viel Abstand, Husten- und Niesetikette, guter Lüftung und dem inzwischen weitgehend etablierten Tragen von Masken zurückgeführt werden kann und die Hygienemaßnahmen wirken.

Auf Grundlage dieser Daten erscheint das Vorgehen vertretbar, nur wirklich enge KP in Quarantäne zu schicken und den anderen KP mit Hygieneauflagen einschließlich des Tragens eines MundNasen-Schutzes den Besuch der Einrichtung weiter $\mathrm{zu}$ ermöglichen. Nach neueren Fachstellungnahmen [52, 53] kann Kindern ab dem Alter von 6 Jahren das Tragen einer Mund-Nasen-Bedeckung im Alltag zugemutet werden. In Abwägung der Vor- und Nachteile [54] haben wir dies als „mildere Maßnahme“ als die Quarantänisierung gewertet und konnten so auf einen Ausschluss der $\mathrm{KP}$ in der Schule verzichten - unter der Voraussetzung, dass alle Anwesenden eine Maske tragen. Das strukturierte Testen der beteiligten Kinder ist dazu geeignet, Superspreading-Events auszuschließen und die Fallnachverfolgung zu gewährleisten. Das Schließen von ganzen Klassen oder Einrichtungen ist hingegen nicht erforderlich.

Bereits in der Frühphase der Pandemie haben die Deutsche Gesellschaft für Krankenhaushygiene (DGKH) und die pädiatrischen Fachgesellschaften in Deutschland und andere Fachgremien gefordert, die Schulen und Kitas offen zu halten bzw. wieder zu öffnen [27, 55-59]. Sie bezogen sich dabei auf die Publikationen, die nicht nur ein geringeres Risiko für schwere Erkrankungen im Kindesalter, sondern auch die vergleichsweise geringe Transmissionsgefahr durch Kinder nachwiesen [60-62]. Dabei wurde insbesondere auch das Recht der Kinder und Jugendlichen auf Bildung und Teilhabe berücksichtigt, sowie die Prävention von negativen Wirkungen auf die Gesundheit der Kinder und ethische Aspekte [63, 64].

Im Sommer haben die DGKH und Vertreter der pädiatrischen Fachgesellschaften ein umfangreiches Papier vorgelegt, zu „Maßnahmen zur Aufrechter- haltung eines Regelbetriebs und zur Prävention von SARS-CoV-2-Ausbrüchen in Einrichtungen der Kindertagesbetreuung oder Schulen unter Bedingungen der Pandemie und Kozirkulation weiterer Erreger von Atemwegserkrankungen “ [57]. Letztendlich zeigen die hier vorgelegten Daten der KP-Untersuchungen mit geringer Anzahl an Sekundärfällen in Schulen und Kitas, dass diese Konzepte insgesamt gut funktionieren (können).

Die DGKH „sieht eine Fülle kreativer und noch nicht genutzter Hygieneoptionen, die ausgeschöpft werden sollten, bevor stereotyp nur der Weg der Verschärfung durch bloße Kontakteinschränkungen eingeschlagen wird" [59]. In der gemeinsamen Stellungnahme der Deutschen Gesellschaft für Krankenhaushygiene e. V. und der Deutschen Akademie für Kinder- und Jugendmedizin e. V. wird festgestellt: „Die Orientierung am besten Interesse der Kinder (siehe Kinderrechtskonvention) ist hierbei oberstes Gebot. Mit angemessenen Maßnahmen des Schutzes und der Hygiene können von außen in die Einrichtung hinein getragene Infektionen nicht gänzlich verhindert, aber eng begrenzt werden und stören dann nicht die Funktion der gesamten Institution. Mit solchen Maßnahmen können die Gemeinschaftseinrichtungen darüber hinaus zur Infektionsprävention in der gesamten Gesellschaft beitragen" [59].

\section{Limitationen}

Die Meldedaten (Anzahl und Inzidenzen) werden nicht nur von der Krankheitslast, sondern auch von der eingesetzten Testmethode (einschließlich der Probenahme) sowie der vorliegenden Teststrategie und der vorhandenen Testkapazität beeinflusst.

Der niedrige Anteil und die geringere altersbezogene Inzidenz der Kinder unter 15 Jahren im Vergleich zu ihrem Anteil an der Bevölkerung und zur Inzidenz in der Gesamtbevölkerung könnte - insbesondere zu Beginn der Pandemie - durch die damalige Teststrategie beeinflusst sein. Da Kinder sich häufig asymptomatisch infizieren und nur selten schwere Krankheitssymptome bei einer COVID-19-Infektionen entwickeln, standen sie zu Beginn der Pandemie nicht 
im Fokus der Testungen. Insofern könnte die niedrige Inzidenz bei Kindern in der ersten Welle auch durch eine Untererfassung mitbedingt sein. Im Herbst 2020 wurden jedoch umfangreiche Testungen gerade auch im Setting Schule und Kita vorgenommen und dort viele asymptomatische KP getestet, sodass eine systematische Untererfassung COVID-19infizierter Kinder wenig wahrscheinlich ist.

Auch bei den Daten der KP-Untersuchungen sind Limitationen zu beachten: 1) Das Angebot der Untersuchung der KP war freiwillig. Mehr als $85 \%$ der ermittelten KP wurden im Rahmen des Untersuchungsangebotes schließlich getestet. Es kann jedoch nicht sicher ausgeschlossen werden, dass möglicherweise infizierte KP sich nicht oder anderweitig haben testen lassen. Somit kann eine Untererfassung der Positivenrate nicht sicher ausgeschlossen werden. 2) $\mathrm{Da}$ in vielen Fällen unklar blieb, wo sich die Indexfälle und die KP angesteckt haben, kann aus einem Positivnachweis bei einer KP nicht automatisch auf eine Infektion innerhalb der Einrichtung geschlossen werden.

\section{Fazit}

Neben der infektionshygienischen Bewertung von Risiken, die von SARSCoV-2-positiv Getesteten in Kindergemeinschaftseinrichtungen ausgehen, gilt es, auch die soziale und gesellschaftliche Komponente der Betreuung von Kindern in Gemeinschaftseinrichtungen zu bewerten. Aus den hier vorgelegten Daten kann geschlussfolgert werden, dass Infektionsfälle in Kindergemeinschaftseinrichtungen auftreten. Übertragungen im Setting dieser Einrichtungen müssen in jedem Einzelfall betrachtet werden und können grundsätzlich nicht ausgeschlossen werden. Als Infektionstreiber können diese Einrichtungen auf Grundlage der von uns vorgelegten Zahlen jedoch nicht bezeichnet werden. Durch die Meldungen der Einrichtungen (Schulen und Kitas) an das Gesundheitsamt bei dem Bekanntwerden eines Infektionsfalles in der Einrichtung ist es möglich, Fälle im Setting der Einrichtung nachzuverfolgen und die Infektionsketten durch den
Einsatz von strukturierten Testungen zu unterbrechen.

\section{Korrespondenzadresse}

Prof. Dr. Ursel Heudorf

MRE-Netz Rhein-Main, Frankfurt, c/o

Gesundheitsamt Frankfurt am Main

Frankfurt, Deutschland

mre-rhein-main@stadt-frankfurt.de

\section{Einhaltung ethischer Richtlinien}

Interessenkonflikt. U. Heudorf, K. Steul, A. Walczok und R. Gottschalk geben an, dass kein Interessenkonflikt besteht.

Für diesen Beitrag wurden von den Autoren keine Studien an Menschen oder Tieren durchgeführt. Für die aufgeführten Studien gelten die jeweils dort angegebenen ethischen Richtlinien.

\section{Literatur}

1. Word Health Organization (2021)WHOcoronavirus disease (COVID-19) dashboard. https://covid19. who.int/.Zugegriffen:20.02.2021

2. Robert Koch-Institut (2021) Tägliche Situationsberichte. Aktueller Lage-/Situationsbericht des RKI zu COVID-19.https://www.rki.de/DE/Content/InfAZ/ N/Neuartiges_Coronavirus/Situationsberichte/ Gesamt.html.Zugegriffen: 20.02.2021

3. Bialek $S$, Gierke R, Hughes M, McNamara LA, Pilishvili T, Skoff T (2020) Coronavirus disease 2019 in children - United States, February 12-April 2, 2020. Mmwr Morb Mortal Wkly Rep 69(14):422-426

4. Cao Q, Chen Y-C, Chen C-L, Chiu C-H (2020) SARSCoV-2 infection in children: transmission dynamics and clinical characteristics. J Formos Med Assoc 119(3):670-673

5. Castagnoli R, Votto M, Licari A, Brambilla I, Bruno R, Perlini S, Rovida F, Baldanti F, Marseglia GL (2020) Severe acute respiratory syndrome coronavirus 2 (SARS-CoV-2) infection in children and adolescents: a systematic review. JAMA Pediatr. https:// doi.org/10.1001/jamapediatrics.2020.1467

6. Choi SH, Kim HW, Kang JM, Kim DH, Cho EY (2020) Epidemiology and clinical features of coronavirus disease 2019 in children. Clin Exp Pediatr 63(4):125-132. https://doi.org/10.3345/ cep.2020.00535

7. Dong $Y$, Mo X, Hu Y, Qi X, Jiang F, Jiang Z, Tong $S$ (2020) Epidemiology of COVID-19 among children in China. Pediatrics 145(6):e20200702

8. Garazzino $S$, Montagnani $C$, Donà $D$, Meini $A$, Felici E, Vergine G, Bernardi S, Giacchero R, Lo Vecchio A, Marchisio P, Nicolini G, Pierantoni L, Rabbone I, Banderali G, Denina M, Venturini E, Krzysztofiak A, Badolato R, Bianchini S, Galli L, Villani A, Castelli-Gattinara G, The Italian Sitip-Sip Pediatric Infection Study Group (2020) Multicentre Italian study of SARS-CoV-2 infection in children and adolescents, preliminary data as at 10 April 2020. Euro Surveill 25(18):2000600. https://doi. org/10.2807/1560-7917.ES.2020.25.18.2000600

9. Ludvigsson JF (2020) Systematic review of COVID-19 in children shows milder cases and a better prognosis than adults. Acta Paediatr 109(6):1088-1095. https://doi.org/10.1111/apa. 15270

10. She J, Liu L, Liu W (2020) COVID-19 epidemic: disease characteristics in children. J Med Virol 92(7):747-754. https://doi.org/10.1002/jmv. 25807

11. Zimmermann P, Curtis N (2020) Coronavirus infections in children including COVID-19. Pediatr Infect Dis J 39(5):355-368

12. Armann JP, Diffloth N, Simon A, Doenhardt M, Hufnagel M, Trotter A, Schneider D, Hübner J, Berner R (2020) Hospitalisierungen von Kindern und Jugendlichen mit COVID-19. Erste Ergebnisse eines deutschlandweiten Surveys der Deutschen Gesellschaft für Pädiatrische Infektiologie. Dtsch Arztebl Int 117:373-374

13. Streng A, Hartmann K, Armann J, Berner R, Liese JG (2020) COVID-19 bei hospitalisierten Kindern und Jugendlichen. Ein systematischer Review zu publizierten Fallserien (Stand 31.03.2020) und erste Daten aus Deutschland. Monatsschr Kinderheilkd. https://doi.org/10.1007/s00112020-00919-7

14. Merckx J, Labrecque JA, Kaufmann JS (2020) Transmission of SARS-CoV-2 by children. Dtsch Arztebl Int 117(33-34):553-560. https://doi.org/ 10.3238/arztebl.2020.0553

15. Somekh E, Gleyzer A, Heller E, Lopian M, KashaniLigumski L, Czeiger S, Schindler Y, Lessing JB, Stein M (2020) The role of children in the dynamics of intra family coronavirus 2019 spread in densely populated area. Pediatr Infect Dis J 39(8):e202-e204. https://doi.org/10.1097/INF. 0000000000002783

16. Dattner I, Goldberg Y, Katriel G, Yaari R, Gal N, Miron Y, Ziv A, Hamo Y, Huppert A (2020) The role of children in the spread of COVID-19: using household data from Bnei Brak, Israel, to estimate the relative susceptibility and infectivity of children. medRxiv. https://doi.org/10.1101/ 2020.06.03.20121145

17. Maltezou HC, Vorou R, Papadima K, Kossyvakis A, Spanakis N, Gioula G, Exindari M, Metallidis S, Lourida AN, Raftopoulos V, Froukala E, MartinezGonzalez B, Mitsianis A, Roilides E, Mentis A, Tsakris A, Papa A (2020) Transmission dynamics of SARS-CoV-2 within families with children in Greece: a study of 23 clusters. J Med Virol. https:// doi.org/10.1002/jmv.26394

18. Lyngse FP, Kirkeby CT, Halasa T, Andreasen V, Skov RL, Møller FT, Krause TG, Mølbak K (2020) COVID-19 transmission within Danish households: a nationwide study from lockdown to reopening. medRxiv. https://doi.org/10.1101/2020.09.09. 20191239

19. Park YJ, Choe YJ, Park O, Park SY, Kim YM, Kim J, Kweon S, WooY, GwackJ, KimSS, Lee J, Hyun J, Ryu B, Jang YS, Kim H, Shin SH, Yi S, Lee S, Kim HK, Lee H, Jin Y, ParkE, Choi SW, Kim M, Song J, Choi SW, Kim D, Jeon BH, Yoo H, Jeong EK (2020) COVID-19 national emergency response center, epidemiology and case management team. Contact tracing during coronavirus disease outbreak, South Korea, 2020. Emerg Infect Dis 26(10):2465-2468. https://doi. org/10.3201/eid2610.201315

20. Goldstein E, Lipsitch M, Cevik M (2020) On the effect of age on the transmission of SARS-CoV-2 in households, schools and the community. medRxiv. https://doi.org/10.1101/2020.07.19.20157362

21. World Health Organization (2020) China report of the WHO-China joint mission on coronavirus disease 2019 (COVID-19). https://www. who.int/publications/i/item/report-of-the-who- 
china-joint-mission-on-coronavirus-disease2019-(covid-19).Zugegriffen: 19. Aug. 2020

22. Li X, Xu W, Dozier M, He Y, Kirolos A, Lang Z, Song $P$, Theodoratou $E$ (2020) The role of children in the transmission of SARS-CoV2: updated rapid review. J Glob Health 10(2):21101. https://doi.org/ 10.7189/jogh.10.021101

23. Heudorf U, Steul K, Gottschalk R (2020) SarsCov-2 in children-insights and conclusions from the mandatory reporting data in Frankfurt am Main, Germany, March-July 2020. GMS Hyg Infect Control 15:Doc24. https://doi.org/10.3205/ dgkh000359

24. Heudorf U, Steul K, Walczok A, Gottschalk R (2020) Covid-19 in Schulen. Keine Pandemie-,"Treiber". Dtsch Arztebl 117(51-52):A-2505-A-2508

25. Loeffelholz MJ, Tang Y-W (2020) Laboratory diagnosis of emerging human coronavirus infections - the state of the art. Emerg Microbes Infect 9:747-756

26. Bürgeramt Statistik und Wahlen (2019) Statistisches Jahrbuch Frankfurt am Main 2019. https:// frankfurt.de/service-und-rathaus/zahlen-datenfakten/publikationen/statistisches-jahrbuch. Zugegriffen:20.02.2021

27. Schrappe M, Francois-Kettner $H$, Gruhl M, Knieps F, Pfaff H, Glaeske G (2020) Thesenpapiere 1.0-5.0 zu Corona. http://www.matthias.schrappe.com/ akt24.htm. Zugegriffen: 20.02.2021

28. Süddeutsche Gesellschaft für Kinder- und Jugendmedizin (2020) Neue bundesweite Datensammlung von über 110.000 Kindern und Jugendlichen geben entscheidende Hinweise zur Dunkelziffer. Pressemitteilung. https://www.sgkj.de/ images/Aktuell/PM_neue_Daten_zu_Corona_ bei_Kindern.pdf.Zugegriffen: 20.02.2021

29. Süddeutsche Gesellschaft für Kinder- und Jugendmedizin (2020) Ad-Hoc Information zur Datenerhebung an über 100 deutschen Kinderkliniken zu SARS-CoV-2. https://www.sgkj.de/images/ Aktuell/2020-11-24_Ad_Hoc_Information_zur Datenerhebung_an_Kinderklinken.pdf.Zugegriffen: 20.02.2021

30. Gudbjartsson DF, Helgason A, Jonsson H, Magnusson OT, Melsted P, Norddahl GL, Saemundsdottir J, Sigurdsson A, Sulem P, Agustsdottir AB, Eiriksdottir B, Fridriksdottir R, Gardarsdottir EE, Georgsson G Gretarsdottir OS, Gudmundsson KR, Gunnarsdottir TR, Gylfason A, Holm H, Jensson BO, Jonasdottir A, Jonsson F, Josefsdottir KS, Kristjansson T, Magnusdottir DN, le Roux L, Sigmundsdottir G, Sveinbjornsson G, Sveinsdottir KE, Sveinsdottir $M$, Thorarensen EA, Thorbjornsson B, Löve $A$, Masson $G$, Jonsdottir I, Möller AD, Gudnason T, Kristinsson KG, Thorsteinsdottir U, Stefansson K (2020) Spread of SARS-CoV-2 in the Icelandic population. N Engl J Med 382(24):2302-2315. https://doi.org/10.1056/NEJMoa2006100

31. Lavezzo E, Franchin E, Ciavarella C et al (2020) Suppression of a SARS-CoV-2 outbreak in the Italian municipality of Vo'. Nature 584:425-429. https://doi.org/10.1038/s41586-020-2488-1

32. Robert Koch-Institut (2020) Situationsbericht vom 31.12.2020. https://www.rki.de/ DE/Content/InfAZ/N/Neuartiges_Coronavirus/ Situationsberichte/Dez_2020/2020-12-31-de. pdf.Zugegriffen: 20.02 .2021

33. Statistisches Bundesamt (2020) Schulen Lehrkräfte nach Schularten und Beschäftigungsumfang. https://www.destatis.de/DE/Themen/ Gesellschaft-Umwelt/Bildung-ForschungKultur/Schulen/Tabellen/allgemeinbildendeberuflicheschulen-lehrkraefte.html. Zugegriffen: 20.02.2021
34. Statistisches Bundesamt (2020) Beschäftigte in Kindertageseinrichtungen. https://www.destatis. de/DE/Themen/Gesellschaft-Umwelt/Soziales/ Kindertagesbetreuung/Tabellen/beschaeftigtemerkmale-2018.html.Zugegriffen:20.02.2021

35. Ismail SA, Saliba V, Lopez Bernal J, Ramsay ME, Ladhani SN (2020) SARS-CoV-2 infection and transmission ineducational settings: a prospective, cross-sectional analysis of infection clusters and outbreaks in England. Lancet Infect Dis. https:// doi.org/10.1016/S1473-3099(20)30882-3

36. Hamburg \#CoronaHH (2020) Hamburgs Schülerinnen und Schüler infizierten sich außerhalb der Schule offensichtlich vier Mal so häufig wie in der Schule. https://www. hamburg.de/coronavirus/14644922/2020-11-19bsb-coronadaten-schulen/ (und https://www. tagesspiegel.de/wissen/von-bildungsbehoerdeunterdrueckte-corona-studie-einzelne-personloeste-masseninfektion-an-hamburger-schuleaus/26753114.html).Zugegriffen:20.02.2021

37. Stein-Zamir C, Abramson N, Shoob H, Libal E, Bitan M, Cardash T, Cayam R, Miskin I (2020) A large COVID-19 outbreak in a high school 10 days after schools' reopening, Israel, Maa 2020. Euro Surveill 25(29):2001352. https://doi.org/10.2807/ 1560-7917.ES.2020.25.29.2001352

38. Buda S, an der Heiden M, Altmann D, Diercke M, Hamouda O, Rexroth U (2020) Infektionsumfeld von erfassten COVID-19 Ausbrüchen in Deutschland. Epidemiol Bull 38:3-12. https://doi.org/10.25646/ 7093

39. Otte im Kampe E, Lehfeld A, Buda S, Buchholz U, Haas W (2020) Surveillance of COVID-19 school outbreaks, Germany, March to August 2020. Euro Surveill 25(38):2001645. https://doi.org/10.2807/ 1560-7917.ES.2020.25.38.2001645

40. Berner R (2020) Schulen sind keine "silent hotspots". Pressemitteilung der Universität Dresden vom 23.11.2020. https://tu-dresden.de/tudresden/newsportal/news/schulen-sind-keinesilent-hotspots. Zugegriffen: 20.02.2021

41. Fontanet A, Grant R, Tondeur L, Madec Y, Grzelak L, Cailleau I, Ungeheuer M-N, Renaudat C, Fernandes Pellerin S, Kuhmel L, Staropoli I, Anna F, Charneau P, Demeret C, Bruel T, Schwartz O, Hoe B (2020) SARSCoV-2 infection in primary schools in northern France: a retrospective cohort study in an area of high transmission. medRxiv. https://doi.org/10. 1101/2020.06.25.20140178

42. Danis K, Epaulard O, Bénet T, Gaymard A, CampoyS, Bothelo-Nevers Eetal (2020) Cluster of coronavirus disease 2019 (Covid-19) in the French Alps, 2020. Clin Infect Dis 71(15):825-832

43. HeaveyL,Casey G, KellyC, KellyD,McDarby G(2020) No evidence of secondary transmission of COVID19 from children attending school in Ireland, 2020. Euro Surveill 25(21):2000903. https://doi.org/10. 2807/1560-7917.ES.2020.25.21.2000903

44. Yung CF, Kam KQ, Nadua KD, Chong CY, Tan NWH, Li J et al (2020) Novel coronavirus 2019 transmission risk in educational settings. Clin Infect Dis. https:// doi.org/10.1093/cid/ciaa794

45. Dub T, Erra E, Hagberg L, Sarvikivi E, Virta C, Jarvinen A et al (2020) Transmission of SARSCoV-2 following exposure in school settings: experience from two Helsinki area exposure incidents. medRxiv. https://doi.org/10.1101/2020. 07.20.20156018

46. Macartney K, Quinn HE, Pillsbury AJ et al (2020) Transmission of SARS-CoV-2 in Australian educational settings: a prospective cohort study. Lancet Child Adolesc Health 4(11):807-816. https://doi.org/10.1016/S2352-4642(20)30251-0
47. Lopez AS, Hill M, Antezano J, Vilven D, Rutner T, Bogdanow $L$ et al (2020) Transmission dynamics of COVID-19 outbreaks associated with child care facilities-Salt Lake City, Utah, April-July 2020. MMWR Morb Mortal Wkly Rep 69(37):1319-1323. https://doi.org/10.15585/mmwr.mm6937e3

48. Yoon Y, Kim KR, Park H, Kim S, Kim YJ (2020) Stepwise school opening and an impact on the epidemiology of COVID-19 in the children.J Korean Med Sci 35(46):e414. https://doi.org/10.3346/ jkms.2020.35.e414

49. Ehrhardt J, Ekinci $A$, Krehl $H$, Meincke $M$, Finci I, Klein J et al (2020) Transmission of SARS-CoV-2 in children aged 0 to 19 years in childcare facilities and schools after their reopening in May 2020, Baden-Württemberg, Germany. Euro Surveill 25(36):2001587. https://doi.org/10.2807/15607917.ES.2020.25.36.2001587

50. Larosa E, Djuric O, Cassinadri M, Cilloni S, Bisaccia E, Vicentini $M$ et al (2020) Secondary transmission of COVID-19 in preschool and school settings in northern Italy after their reopening in September 2020: a population-based study. Euro Surveill 25(49):2001911. https://doi.org/10.2807/15607917.ES.2020.25.49.2001911

51. Brandal LT, Ofitserova TS, Meijerink H, Rykkvin R, Lund HM, Hungnes O, Greve-Isdahl M, Bragsta K, Nygård K, Winje BA (2021) Minimal transmission of SARS-CoV-2 from paediatric COVID-19 cases in primary schools, Norway, August to November 2020. Euro Surveill 26(1):2002011. https://doi.org/ 10.2807/1560-7917.ES.2020.26.1.2002011

52. Huppertz H-I, Berner R, Schepker R, Kopp M, Oberle A, Fischbach T, Rodeck B, Knuf M, Keller M, Simon A, Hübner J (2020) Verwendung von Masken bei Kindern zur Verhinderung der Infektion mit SARS-CoV-2. https://dgpi.de/covid19-maskenstand-10-11-2020/.Zugegriffen: 20.02.2021

53. Centers for Disease Control and Prevention (2020) CDC COVID-19 (coronavirus disease) guidance for $\mathrm{K}-12 \mathrm{school}$ administrators on the use of masks in schools. https://www.cdc.gov/coronavirus/2019ncov/community/schools-childcare/cloth-facecover.html.Zugegriffen:20.02.2021

54. Spitzner M (2020) Masked education? The benefits and burdens of waering face masks in schools during the current corona pandemic. Trends Neurosci Educ 20:100138. https://doi.org/10. 1016/j.tine.2020.100138

55. Deutsche Gesellschaft für Krankenhaushygiene (2020) Konzept für Strategien zur Folgenminderung (Mitigierung) und zum Schutz gefährdeter Bevölkerungsgruppen (Protection) durch die COVID-19 Epidemie unter Berücksichtigung der Verhältnismäßigkeit. https://www. krankenhaushygiene.de/pdfdata/2020_03 22_DGKH_Mitteilung_Ausgangssperre_RKG_ Konzept.pdf.Zugegriffen: 20.02.2021

56. Walger $P$, Heininger U, Knuf M et al (2020) Children and adolescents in the CoVid-19 pandemic: schools and daycare centers are to be opened again without restrictions. The protection of teachers, educators, carers and parents and the general hygiene rules do not conflict with this. GMS Hyg Infect Control 15:Doc11. https://doi.org/ 10.3205/dgkh000346

57. Simon A, Huebner J, Berner R, Munro APS, Exner M, HuppertzHI, Walger P(2020) Measures to maintain regular operations and prevent outbreaks of SARSCoV-2 in childcare facilities or schools under pandemic conditions and co-circulation of other respiratory pathogens. GMS Hyg Infect Control 15:Doc22. https://doi.org/10.3205/dgkh000357 
58. Deutsche Gesellschaft für Krankenhaushygiene, Deutsche Akademie für Kinder-und Jugendmedizin (2020) Auch unter hohen SARS-CoV-2 Infektionszahlen können Gemeinschaftseinrichtungen für Kinder und Jugendliche geöffnet bleiben, wenn die Hygieneregeln (AHA-L) bei zusätzlichen betrieblich-organisatorischen Maßnahmen eingehalten werden. https://www. krankenhaushygiene.de/pdfdata/2020_11_20 Stellungnahme_DGKH_DAKJ_Kinder.pdf. Zugegriffen: 20.02.2021

59. Deutsche Gesellschaft für Krankenhaushygiene (2020) Aktuelle epidemiologische Daten unterschiedlicher Studien aus Deutschland lassen die Interpretation zu: Lasst die Schulen und Kitas grundsätzlich offen! https://www. krankenhaushygiene.de/pdfdata/2020_11_20 PM_DGKH_Kinder.pdf.Zugegriffen:20.02.2021

60. Viner RM, Russell SJ, Croker H, Packer J, Ward J, Stansfield C, Mytton O, Bonell C, Booy R (2020) School closure and management practices during coronavirus outbreaks including COVID-19: a rapid systematic review. Lancet Child Adolesc Health 4(5):397-404. https://doi.org/10.1016/S23524642(20)30095-X

61. European Centre for Disease Prevention and Control (2020) COVID-19 in children and the role of school settings in COVID-19 transmission. https://www.ecdc.europa.eu/sites/default/files/ documents/COVID-19-schools-transmissionAugust\%202020.pdf.Zugegriffen: 20.02.2021

62. European Centre for Disease Prevention and Control (2020) COVID-19 in children and the role of school settings in COVID-19 transmission. https://www.ecdc.europa.eu/en/publicationsdata/children-and-school-settings-covid-19transmission. Zugegriffen:20.02.2021

63. Ravens-Sieberer U, Kasman A, Otto C, Adedej A, Devine J, Erhart M, Napp AK, Becker M, BlanckStellmacher U, Löffler C, Schlack R, Hurrelmann K (2020) Mental health and quality of life in children and adolescents during the COVID-19 pandemic - results oft he COPSY study. Dtsch Arztebl Int 117:828-829. https://doi.org/10.3238/ arztebl.2020.0828

64. Silverman M, Sibbald R, Stranges S (2020) Ethics of COVID-19-related school closures. Can J Public Health. https://doi.org/10.17269/s41997-02000396-1

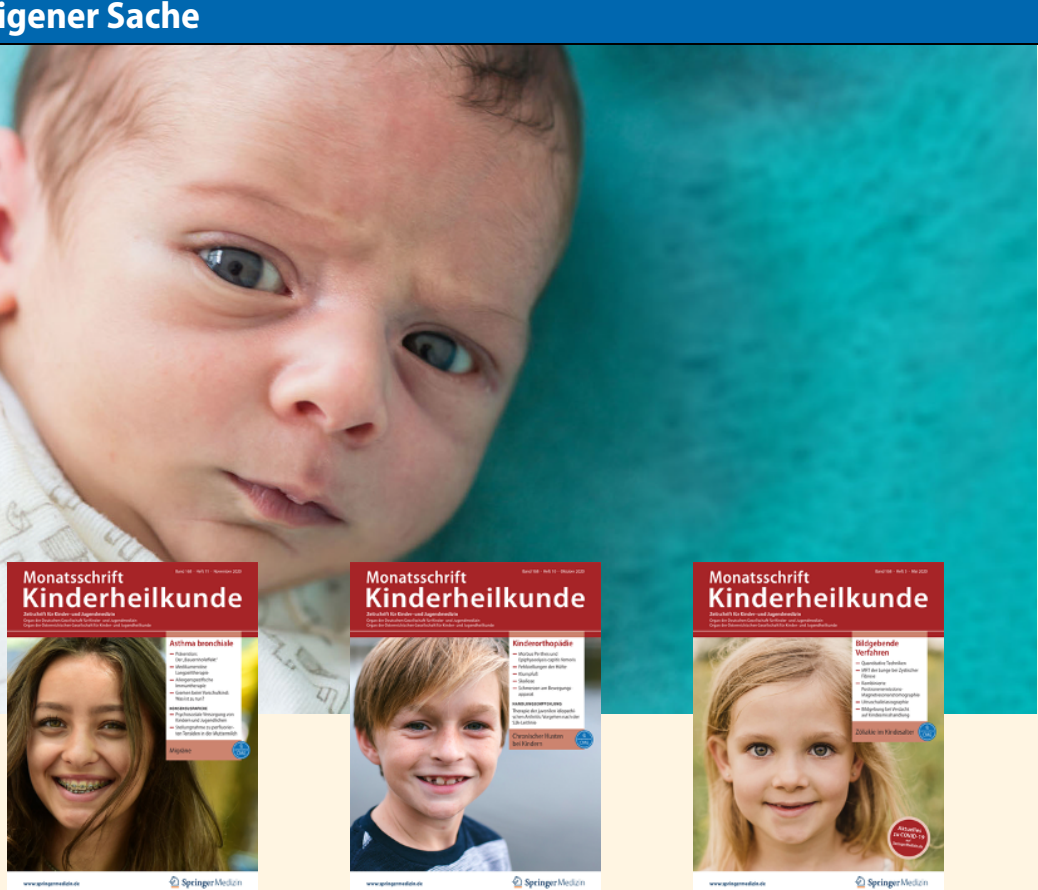

\section{Leitthemenübersicht Monatsschrift Kinderheilkunde 2021}

\section{Die Zeitschrift Monatsschrift Kinderheilkunde bietet Ihnen jeden Monat umfas- sende und aktuelle Beiträge zu interessanten Themenschwerpunkten aus allen Bereichen der Pädiatrie.}

$-01 / 2021$
$-02 / 2021$
$-03 / 2021$
$-04 / 2021$
$-05 / 2021$
$-06 / 2021$
$-07 / 2021$
$-08 / 2021$
$-09 / 2021$
$-10 / 2021$
$-11 / 2021$
$-12 / 2021$

Pädiatrische Onkologie

Haut und Hauterkrankungen

Rehabilitation

Aktuelles zu COVID-19

Fieber

Politische Kindermedizin

Psychosomatische Störungen

Digitalisierung und Künstliche Intelligenz

Molekulare Pädiatrie

Diabetes

Impfungen

Neonatologie

Alle Inhalte von Monatsschrift Kinderheilkunde finden Sie unter

www.springermedizin.de/monatsschrift-kinderheilkunde.

SpringerMedizin.de bietet Ihnen Zugang zu allen elektronisch verfügbaren Ausgaben Ihrer Zeitschrift - unabhängig vom Beginn Ihres Abonnements.

Möchten Sie ein bereits erschienenes Heft nachbestellen? Einzelne Ausgaben können Sie direkt bei unserem Kundenservice zum Preis von je EUR 45,- zzgl. Versandkosten beziehen.

\section{So erreichen Sie unseren Kundenservice:}

Springer Customer Service Center GmbH

Kundenservice Zeitschriften

Tiergartenstr. 15, 69126 Heidelberg

Tel.: +496221345-4303

Fax: +496221345-4229

E-Mail: leserservice@springer.com 